\title{
HUBUNGAN ANTARA STATUS GIZI DAN OLAH RAGA DENGAN KEJADIAN DISMENORE PADA MAHASISWI JURUSAN KEBIDANAN RANGKASBITUNG TAHUN 2015
}

\author{
*Nintinjri Husnida, *Hani Sutianingsih
}

\begin{abstract}
Abstrak
Dismenore adalah nyeri haid yang biasanya bersifat kram dan berpusat pada perut bagian bawah yang terasa sebelum atau selama menstruasi, terkadang sampai parah sehingga mengganggu aktivitas. Nyeri bisa semakin bertambah karena disamping stres, kurang berolahraga dan gizi yang tidak seimbang / status gizi yang kurang baik. Angka kejadian Dismenore di dunia sangat besar. Ratarata lebih dari $50 \%$ perempuan disetiap negara mengalami Dismenore. Di Amerika angka prosentasenya sekitar $60 \%$ dan di Swedia sekitar $72 \%$. Sementara di Indonesia angkanya diperkirakan $55 \%$ perempuan usia produktif yang mengalami Dismenore. Dari hasil survei pendahuluan yang telah dilakukan pada 76 mahasiswi jurusan kebidanan rangkasbitung, ditemukan 73,6 \% mahasiswi mengalami dismenore dan beberapa diantaranya sangat menganggu aktivitas mereka pada saat diasrama dan pada saat kuliah mulai dari keluhan gangguan rasa nyaman, tidak nafsu makan, mual, muntah, sakit pinggang, tidak bisa fokus dan konsentrasi pada saat kuliah bahkan sampai pingsan.

Penelitian ini bertujuan untuk mengetahui hubungan antara status gizi dan olahraga pada mahasiswa Jurusan Kebidanan Rangkasbitung Poltkkes Kemenkes Banten tahun 2015. Jenis penelitian ini adalah kuantitatif dengan metode studi analitik korelatif menggunakan pendekatan Cross Sectional. Jumlah sampel yang digunakan 161 responden, dengan menggunakan total populasi. Data penelitian diambil secara primer menggunakan kuesioner. Analisis data untuk mengetahui hubungan antar variabel menggunakan Chi-Square.

Hasil penelitian secara univariat menunjukkan tingginya angka kejadian dismenore pada mahasiswi jurusan kebidanan rangkasbitung sebesar $72 \%$, status gizi yang tidak normal sebesar 18,6 \% dan mahasiswi yang tidak melakukan olahraga sebanyak $23 \%$. Dari hasil uji bivariat didapatkan bahwa tidak ada hubungan yang signifikan antara status gizi dan olahraga dengan dismenore.

Saran untuk Jurusan Kebidanan Rangkasbitung meningkatkan pemahaman melalui pencarian informasi dari berbagai sumber melalui jurnal terkini dan dapat memanfaatkan program PIK-M pada kegiatan kemahasiswaan guna mencegah dan menanggulangi masalah dismenore.

Kata kunci : Status gizi, Olahraga, Dismenore

*Poltekkes Kemenkes Banten
\end{abstract}




\title{
THE RELATION BETWEEN NUTRITIONAL STATUS AND EXERCISES WITH DYSMENORRHOE TOWARDS STUDENTS OF MIDWIFERY MAJOR IN RANGKASBITUNG IN 2015
}

\author{
*Nintinjri Husnida, *Hani Sutianingsih
}

\begin{abstract}
Dysmenorrhoe is the illness causes by menstruation that usually cause cramps in lower abdomen, and it occurs before or during menstruation, that intervere persons activity. The illness can be worse causes by lack of exercise, inadequate nutrition ang stress. The prevalence of Dysmenorrhoe is about 50\% in the world. In united States di prevalence of Dysmenorrhoe is 60\%, in Sweden $72 \%$ while in Indonesia it's estimated 55\%.

Based on preliminary survey that was conducted on 76 female students of midwifery major in Rangkasbitung, found 56 student experience dysmenorrhea and some of them very disturbing their activities in the dormitory and during lecture. The form of the symptom are varies like loss of appetite, nausea, vomiting, pain, unfocus and lack of concentration during lectures even unconscious.

This study aims to investigate the relationship between nutritional status and health in students of midwifery major in Rangkasbitung, Poltekkes Banten 2015. This research is a quantitative method correlative analytic study using cross sectional approach. The samples used 161 respondents, by using the total population. Primary research data are taken by using a questionnaire. The data were analyzed to determine the relationship between variables using Chi-Square.

The results showed no significant relationship between nutritional status with dysmenorrhea and there is no significant relationship between exercise with dysmenorrhea.

Advice to the Department of midwifery major in Rangkasbitung is to optimize the role of student organizations of reproductive health in an effort to avoid and cope with dysmenorrhea
\end{abstract}

Keywords $\quad$ : Nutritional status, Exercise, Dysmenorrhea 


\section{Pendahuluan}

Masa remaja adalah masa transisi yang ditandai oleh adanya perubahan fisik, emosi dan psikis. Menurut Depkes RI masa remaja, yakni antara usia 10-19 tahun dan belum kawin sedangkan menurut WHO adalah 12 sampai 24 tahun, dimana pada masa ini merupakan suatu periode masa pematangan organ reproduksi manusia, dan sering disebut pubertas. Salah satu kejadian penting pada masa pubertas terjadinya menarche atau menstruasi yang pertama kali terjadi. (Widyastuti dkk, 2009)

Gangguan ginekologi pada masa remaja yang sangat sering terjadi adalah gangguan yang berhubungan dengan siklus menstruasi, pendarahan uterus disfungsi, yang termasuk di dalamnya adalah dismenore, premenstrual syndrome, dan hirsutisme. Gangguan yang paling sering terjadi adalah dismenore. (Edmonds K, 2007)

Dismenore adalah nyeri haid yang biasanya bersifat kram dan berpusat pada perut bagian bawah yang terasa sebelum atau selama menstruasi, terkadang sampai parah sehingga mengganggu aktivitas. (Anwar Mochamad 2011).

Nyeri bisa semakin bertambah karena disamping stres, kurang berolahraga dan gizi yang tidak seimbang / status gizi yang kurang baik, penyebab lain timbulnya nyeri yang luar biasa adalah penyakit seperti endometriosis dan tumor pada rahim. (Marmi, 2013)

Angka kejadian Dismenore di dunia sangat besar. Rata-rata lebih dari $50 \%$ perempuan disetiap negara mengalami Dismenore. Di Amerika angka prosentasenya sekitar 60\% dan di Swedia sekitar $72 \%$. Sementara di Indonesia angkanya diperkirakan 55\% perempuan usia produktif yang mengalami Dismenore. (Marmi, 2013)

Dari beberapa hasil penelitian di Indonesia antara lain di SMAN 1 Kahu Kabupaten Bone Provinsi Sulawesi Selatan tahun ajaran 2012/2013, sampel sebanyak 232 orang didapatkan hasil 87,1\% siswi tersebut mengalami dismenore. (Utami Andi, 2013). Penelitian ditempat lain pada siswi SMK 
Negeri 10 Medan tahun 2013 menunjukkan angka yang cukup tinggi yaitu $81,30 \%$ dari 171 siswi. (Sophia frenita, 2013)

Sementara penelitian di SMPN

3 Manado didapatkan bahwa sebagian besar responden $(98,5 \%)$ pernah mengalami dismenore dan hanya sedikit (1,5\%) yang tidak mengalaminya. (Lestari hesti dkk, 2010)

Dari hasil survei pendahuluan yang telah dilakukan pada tanggal 17 April 2015 pada 76 mahasiswi jurusan kebidanan rangkasbitung, ditemukan 56 mahasiswi mengalami dismenore dan beberapa diantaranya sangat menganggu aktivitas mereka pada saat diasrama dan pada saat kuliah mulai dari keluhan gangguan rasa nyaman, tidak nafsu makan, mual, muntah, sakit pinggang, tidak bisa fokus dan konsentrasi pada saat kuliah bahkan sampai pingsan.

\section{Metodologi Penelitian}

Penelitian ini merupakan penelitian kuantitatif dengan pendekatan cross sectional yang menganalisis mengenai Hubungan Status Gizi Dan Olahraga Dengan
Kejadian Dismenore Pada Mahasiswi Jurusan Kebidanan Rangkasbitung. Populasi penelitian adalah seluruh mahasiswi tingkat 1 dan 2 jurusan kebidanan poltekkes kemenkes banten yang berjumlah 161 .

\section{Hasil}

\section{Karakteristik Responden}

Karakteristik responden yang diteliti adalah status gizi, olahraga dan kejadian dismenore. Dalam pengolahan data, variabel status gizi dibedakan menjadi 2 kategori yaitu normal dengan nilai IMT 18,5 -25,0 dan tidak normal bila nilai IMT $<17,0-18,5$ atau $>25,0$. Sedangkan variabel olah raga dibedakan dalam kategori ya apabila dilakukan setiap $3-5 x$ per minggu dengan durasi minimal 30-60 menit dan Tidak apabila dilakukan $<3$ kali dalam seminggu dan durasi kurang dari 30 menit.

\section{Analisis Univariat}

Distribusi karakteristik responden dapat dilihat pada tabel 1 berikut ini: 
Tabel 1

Distribusi Frekuensi Mahasiswi Berdasarkan Karakteristik Tahun 2015

\begin{tabular}{|c|c|c|c|c|c|c|c|}
\hline \multicolumn{2}{|c|}{ No } & \multicolumn{3}{|c|}{$\begin{array}{c}\text { Karakteristik } \\
\text { Responden }\end{array}$} & $\mathrm{F}$ & \multicolumn{2}{|l|}{$\%$} \\
\hline \multirow{3}{*}{ No } & \multirow{3}{*}{$\begin{array}{l}\text { Status } \\
\text { gizi }\end{array}$} & \multicolumn{4}{|c|}{ Dismenore } & \multirow{2}{*}{\multicolumn{2}{|c|}{ Total }} \\
\hline & & \multicolumn{2}{|c|}{ Ya } & \multicolumn{2}{|c|}{ Tidak } & & \\
\hline & & $\mathrm{N}$ & $\%$ & $\mathrm{~N}$ & $\%$ & $\mathrm{~N}$ & $\%$ \\
\hline 1 & Normal & 92 & 70.2 & 39 & 29.8 & 131 & 100 \\
\hline \multirow[t]{2}{*}{2} & $\begin{array}{l}\text { Tidak } \\
\text { Normal }\end{array}$ & 24 & 80.0 & 6 & 20.0 & 30 & 100 \\
\hline & Total & 116 & 72.0 & 45 & 28.0 & 161 & 100 \\
\hline
\end{tabular}

1. Status Gizi

a. Normal $\quad 131 \quad 81.4$

b. Tidak normal $\quad 30 \quad 18,6$ Jumlah $\quad 161 \quad 100$

2. Olahraga

$\begin{array}{llll}\text { a. Ya } & 37 & 23,0\end{array}$

b. Tidak $\quad 124 \quad 77,0$

Jumlah $\quad 161 \quad 100$

3. Dismenore

\begin{tabular}{llcc} 
a. & Ya & 116 & 72,0 \\
b. & Tidak & 45 & 28,0 \\
& Jumlah & 161 & 100 \\
\hline
\end{tabular}

Berdasarkan karakteristik responden pada tabel 1 diketahui kategori status gizi 18,6 \% adalah status gizi tidak normal. Hasil distribusi karakteristik responden selanjutnya sebagian besar responden yang tidak melakukan olah raga sebesar $77 \%$ Sedangkan berdasarkan kejadian dismenore bahwa sebagian besar responden mengalami kejadian dismenore $72 \%$.

\section{Analisis Bivariat}

Uji chi square digunakan dalam melakukan analisis bivariat. Tabel-tabel berikut ini menyajikan hasil analisis bivariat antara variabel status gizi, olahraga dengan dismenore.

Tabel 2

Hubungan Antara Status Gizi dengan Dismenore Pada

Mahasiswi Jurusan Kebidanan

Rangkasbitung Tahun 2015

Berdasarkan tabel silang 2 menunjukkan bahwa kejadian dismenore lebih banyak $(80,0 \%)$ pada Mahasiswi yang memiliki status gizi tidak normal, jika dibandingkan dengan mahasiswi yang memiliki status gizi normal hanya $70,2 \%$ yang mengalami dismenore.

Hasil uji statistik, diketahui bahwa nilai $p$ pada analisis bivariat dengan uji chi square adalah 0.395 $(\mathrm{P}>0,05)$ dapat diartikan bahwa tidak ada hubungan yang signifikan antara status gizi dengan Kejadian dismenore. 
Tabel 3

Hubungan Antara Olah Raga dengan Kejadian Dismenore Pada Mahasiswi Kebidanan Rangkasbitung Tahun 2015

\begin{tabular}{|c|c|c|c|c|c|c|c|}
\hline \multirow{3}{*}{ No } & \multicolumn{7}{|c|}{ Dismenore } \\
\hline & \multirow{2}{*}{$\begin{array}{l}\text { Olah } \\
\text { raga }\end{array}$} & \multicolumn{2}{|c|}{$\mathrm{Ya}$} & \multicolumn{2}{|c|}{ Tidak } & \multicolumn{2}{|c|}{ Total } \\
\hline & & $\mathrm{N}$ & $\%$ & $\mathrm{~N}$ & $\%$ & $\mathrm{~N}$ & $\%$ \\
\hline 1 & $\mathrm{Ya}$ & 22 & 59.5 & 15 & 40.5 & 37 & 100 \\
\hline \multirow[t]{2}{*}{2} & Tidak & 94 & 75.8 & 30 & 24.2 & 124 & 100 \\
\hline & Total & 116 & 72.0 & 45 & 28.0 & 161 & 100 \\
\hline
\end{tabular}

Berdasarkan tabel 3 diatas

menunjukkan bahwa kejadian dismenore lebih banyak terjadi $(75,8 \%)$ pada mahasiswi yang tidak melakukan oleh raga, jika dibandingkan dengan mahasiswi yang melakukan olah raga hanya $59,5 \%$ yang mengalami dismenore.

Dari hasil Uji statistik diketahui bahwa nilai $p$ pada analisis bivariat dengan uji chi square adalah 0.083 dapat diartikan bahwa tidak ada hubungan yang signifikan antara olahraga dengan dismenore.

\section{Pembahasan}

\section{Status gizi}

Kesehatan reproduksi remaja adalah upaya kesehatan reproduksi yang dibutuhkan oleh remaja. Salah satu unsur yang berperan dalam mewujudkan kesehatan reproduksi pada remaja adalah status gizi. Asupan zat-zat gizi yang seimbang dan sesuai dengan kebutuhan remaja akan membantu remaja mencapai pertumbuhan dan perkembangan yang optimal. Ketidakseimbangan antara asupan kebutuhan atau kecukupan akan menimbulkan masalah gizi baik itu berupa masalah gizi lebih maupun gizi kurang. (Sulistyoningsih, 2012)

Status gizi merupakan suatu ukuran mengenai kondisi tubuh seseorang yang dapat dilihat dari makanan yang dikonsumsi dengan penggunaan zat-zat gizi di dalam tubuh dan dihitung berdasarkan indeks masa tubuh yang dihitung berdasarkan berat badan dibagi tinggi badan dalam $\mathrm{m}^{2}$ yang dikategorikan yaitu Kurus : $<17,0$ 18,5 Normal: 18,5 -25,0 Gemuk : > 25,0 (Supariasa, 2001)

Responden penelitian ini yaitu masih terdapat jumlah mahasiswi dengan status gizi yang tidak normal yaitu 18,6 \%. Meskipun angka ini lebih kecil bila dibandingkan angka status gizi normal tetapi dalam hal ini status gizi yang tidak normal merupakan indikator masih terdapat 
status gizi yang kurang atau justru berlebih.

Status gizi yang kurang, identik mengalami anemia yang merupakan salah satu faktor konstitusi yang dapat menyebabkan kurangnya daya tahan tubuh terhadap rasa nyeri sehingga saat menstruasi dapat terjadi dismenore, anemia juga diakibatkan karena kurangnya mengkonsumsi makanan yang mengandung zat besi. Jika mengalami anemia maka daya tahan tubuh akan berkurang sehingga menyebabkan nyeri di saad haid. Status gizi yang lebih yaitu lemak yang berlebihan yang dapat memicu timbulnya hormon yang dapat mengganggu sistem reproduksi termasuk pada waktu menstruasi yaitu menimbulkan nyeri haid. (Rayne, 2014)

Meskipun status gizi mahasiswi jurusan kebidanan terbilang lebih tinggi yang normal dari pada yang tidak normal, namun demikian hal ini perlu diperhatikan. Masih terdapatnya satus gizi yang tidak normal bisa dikarena kan mahasiswi kurang memperhatikan pola mahan sehari hari. Faktor lain bisa juga dikarenakan mahasiswi kurang menyukai jenis makanan tertentu yang dapat meningkatkan atau memperbaiki status gizi tersebut sehingga mereka tidak memakan makanan tersebut.

Salah satu upaya yang dapat dilakukan untuk meningkatkan status gizi dengan menjaga pola makan baik dari waktu maupun jenis makanan. Selain itu pola hidup yang sehat juga akan mempengaruhi kondisi status seseorang. Dengan menghindari stress, maka pola makan akan terjaga dan tidak mengalami anemia.

\section{Olahraga}

Berdasarkan Tabel 1 distribusi menunjukkan bahwa sebagian besar responden yang tidak melakukan olah raga sebesar $77 \%$ dan hanya $23 \%$ yang melakukan olahraga.

Olahraga adalah suatu bentuk aktivitas fisik yang terencana dan terstruktur yang melibatkan gerakan tubuh berulang-ulang dan ditujukan untuk meningkatkan kebugaran jasmani. Jenis olahraga antara lain aerobik dan anaerobik. Aerobik adalah olahraga yang dilakukan 
secara terus menerus dimana kebutuhan oksigen masih dapat dipenuhi tubuh. Misalnya: jogging, senam, renang, bersepeda. Sedangkan anaerobik adalah olahraga dimana kebutuhan oksigen tidak dapat dipenuhi seluruhnya oleh tubuh. Misalnya: angkat besi, lari sprint 100 meter, tenis lapangan, bulu tangkis. Wanita yang melakukan olahraga secara teratur setidaknya 30-60 menit setiap 3-5x per minggu dapat mencegah terjadinya dismenore. Setiap wanita dapat sekedar berjalan-jalan santai, jogging ringan, berenang, senam maupun bersepeda sesuai dengan kondisi masing-masing. (Manuaba 2010)

Melakukan Olahraga dengan frekuensi yang benar akan menjaga stamina dan ketahanan aliran darah seseorang terjaga. Stamina akan menurun kembali setelah 48 jam tidak melakukan latihan. Sebelum stamina dan ketahanan menurun kembali diusahakan berlatih fisik. (Giriwijoyo, 2012).

Tingginya angka mahasiswi yang tidak olahraga dimungkinkan karena padatnya proses belajar mengajar dikampus dan aktivitas diasrama, sehingga mahasiswa tidak mempunya waktu khusus untuk melakukan olahraga. Penyebab lain bisa juga dikarenakan mahasiswi kurang memiliki minat, bakat ataupun motivasi sehingga mahasiswi tidak memanfaatkan sarana dan prasarana olahraga yang tersedia di kampus.

Salah satu upaya agar mahasiswa melakukan olahraga adalah dengan meningkatkan keaktifan kegiatan khususnya dibidang olahraga yang dijadualkan secara rutin diluar perkuliahan agar juga tidak mengganggu proses belajar mengajar. Apabila hal ini dilaksanakan, maka kemungkinan terjadinya dismenore dapat dihindari.

3. Dismenore

Berdasarkan tabel distribusi diketahui bahwa sebagian besar responden mengalami kejadian dismenore $72 \%$.

Dismenorea atau yang lebih dikenal dengan nama nyeri haid adalah keluhan yang sering dialami pada remaja putri tepatnya di perut bagian bawah. Dismenorea merupakan penyakit yang sudah 
cukup lama dikenal. Nyeri tersebut dapat disertai mual, muntah, diare, berkeringat dingin, dan pusing. Namun belakangan diketahui bahwa nyeri ketika haid tidak hanya dirasakan dibagian perut bagian bawah saja. Beberapa remaja terkadang merasakan dibagian punggung bagian bawah, pinggang, panggul otot paha atas hingga betis. (Ernawati, 2015)

Dismenore adalah nyeri di perut bagian bawah ataupun di pungung bagian bawah akibat dari gerakan rahim yang meremas remas (kontraksi) dalam usaha untuk mengeluarkan lapisan dinding rahim yang terlepas. Dismenorea atau nyeri haid merupakan gejala, bukan penyakit. Gejalanya terasa nyeri di perut bagian bawah. Pada kasus dismenorea berat, nyeri terasa sampai seputaran panggul dan sisi dalam paha. Nyeri terutama pada hari pertama dan kedua menstruasi. Nyeri akan berkurang setelah keluar darah menstruasi yang cukup banyak. Pada saat haid, pada sebagian perempuan ada yang mengalami gangguan haid yang cukup berat. Salah satu gangguan yang berhubungan dengan haid adalah dismenore. Tidak sedikit perempuan mengalami nyeri haid berkepanjangan yang terus menerus mengalami rasa sakit, bahkan tidak bisa beraktivitas apapun selama haid karena rasa nyeri yang tidak tertahankan. Tingginya angka kejadian ini bisa disebabkan karena berbagai faktor. Sejalan dengan teori bahwa dismenore dapat disebabkan faktor konstitusi seperti anemia, faktor alergi, stress, tidak pernah berolah raga dll. (Manuaba, 2010)

Upaya untuk menurunkan atau mencegah kejadian dismenore adalah dengan meningkatkan status gizi dan kegiatan olahraga secara rutin. Dengan demikian dismenore dapat dicegah dan upaya penanganan dismenore dapat diatasi.

4. Hubungan status gizi dengan Dismenore

Asupan zat-zat gizi yang seimbang dan sesuai dengan kebutuhan remaja akan membantu remaja mencapai pertumbuhan dan perkembangan yang optimal. Ketidakseimbangan antara asupan kebutuhan atau kecukupan akan 
menimbulkan masalah gizi baik itu berupa masalah gizi lebih maupun gizi kurang. (Sulistyoningsih, $\mathrm{H}$, 2012)

Menurut Sulistyoningsih, berbagai perubahan terjadi pada diri remaja baik itu perubahan fisik, biologis maupun perubahan psikis. Masa remaja merupakan periode pertumbuhan dan proses kematangan manusia, sehingga terjadi perubahan yang sangat unik dan berkelanjutan. Pertumbuhan fisik pada remaja terjadi secara bersamaan dengan proses matangnya organ reproduksi.

Pada remaja wanita perlu mempertahankan status gizi yang baik, dengan cara mengkonsumsi makanan seimbang karena sangat dibutuhkan pada saat haid, terbukti pada saat haid tersebut terutama pada fase luteal akan terjadi peningkatan kebutuhan nutrisi. Apabila hal ini diabaikan maka dampaknya akan terjadi keluhan - keluhan yang menimbulkan rasa ketidaknyamanan selama siklus haid. (Proverawati, A dan As Fuash,S. 2009)

Hasil ini juga tidak sejalan dengan penelitian yang pernah dilakukan oleh Sophia yaitu terdapat hubungan yang bermakna antara status gizi dengan kejadian dismenore pada siswi SMK Negeri 10 Medan tahun 2013 dan menyatakan dari 139 siswi dengan status gizi rendah (underweight) memiliki kemungkinan resiko 1,2 kali lebih besar mengalami dismenore dibandingkan dengan siswi dengan status gizi normal. (Sophia Frenita, 2013)

Hasil penelitian lain yang pernah dilakukan Riyane Manorek juga menyatakan dimana semakin banyak status gizi yang tidak beresiko (normal) maka semakin sedikit juga kejadian dismenore pada siswi.

Tidak adanya hubungan anatara status gizi dengan dismenore ini bisa disebabkan karena status gizi yang tidak normal pada mahasiswi bukan karena anemia yang dapat memicu dismenore. Kondisi tubuh yang kurus atau terlalu gemuk dapat dimungkinkan juga karena faktor keturunan . Tidak sejalan nya hasil ini dengan beberapa penelitian juga bisa karena faktor lain yang menyertai seperti riwayat keluarga (ibu atau sodara perempuan 
kandung) yang merupakan salah satu faktor risiko dismenore. Kondisi anatomi dan fisiologis dari seseorang pada umumnya hampir sama dengan orang tua dan saudara-saudaranya.

Kemungkinan lain yang dapat memicu yaitu lamanya menstruasi. Semakin lama menstruasi terjadi, maka semakin sering uterus berkontraksi, akibatnya semakin banyak pula prostaglandin yang dikeluarkan. Akibat prostaglandin yang berlebihan maka timbul rasa nyeri pada saat menstruasi. Sehingga tidak adanya hubungan yang signifikan antara status gizi dengan kejadian dismenore pada penelitian ini dapat diakibatkan dari kemungkinan faktor lain yang tidak diteliti.

5. Hubungan Olahraga dengan Dismenore

Berdasarkan tabel silang 3 diketahui bahwa nilai $p$ pada analisis bivariat dengan uji chi square adalah 0.083 dapat diartikan bahwa tidak ada hubungan yang signifikan antara olahraga dengan dismenore.

Kejadian dismenore akan meningkat pada wanita yang kurang melakukan olahraga, sehingga ketika wanita mengalami dismenore, oksigen tidak dapat disalurkan ke pembuluh-pembuluh darah organ reproduksi yang saat itu terjadi vasokontriksi. Bila wanita teratur melakukan olahraga, maka wanita tersebut dapat menyediakan oksigen hampir 2 kali lipat per menit sehingga oksigen tersampaikan ke pembuluh darah yang mengalami vasokontriksi. Hal itu akan menyebabkan terjadinya penurunan kejadian dismenore dengan teratur berolahraga. (Tjokronegoro, 2004).

Salah satu cara yang efektif untuk mencegah dismenore adalah dengan cara melakukan olahraga. Beberapa latihan fisik dapat meningkatkan pasokan darah ke organ reproduksi sehingga memperlancar peredaran darah. Olahraga yang dilakukan sekurangkurangnya tiga kali seminggu. Perempuan yang melakukan olahraga secara teratur dapat meningkatkan sekresi hormon endhorphin yaitu penghilang nyeri alami ke dalam aliran darah sehingga dapat mengurangi Dismenore. (Mutohir, 2004) 
Hasil penelitian ini tidak hubungan kemungkinan berasal dari sejalan dengan ramadani bahwa siswi dengan olahraga baik yang tidak Dismenore lebih banyak dari pada yang disminore. Hal ini disebabkan karena siswi yang membiasakan olahraga dan aktivitas fisik secara teratur dapat meringankan rasa tidak nyaman termasuk Dismenore karena dapat membantu relaksasi saat fase haid. (Ramadani, 2014)

Dari penelitian lain, hasil ini tidak sejalan juga dengan penelitian yang pernah dilakukan Sophia yaitu terdapat hubungan yang bermakna antara kebiasaan olahraga dengan kejadian dismenore. Siswi yang jarang berolahraga memiliki kemungkinan risiko 1,2 kali lebih besar mengalami dismenore daripada siswi yang sering berolahraga. (Sophia Frenita, 2013)

Tidak adanya hubungan
yang bermakna antara olahraga
dengan kejadian dismenore dapat
disebabkan karena olahraga hanya
merupakan salah satu teknik
relaksasi yang dapat digunakan
untuk mengurangi nyeri. Faktor lain
yang menyebabkan tidak adanya
ambang sakit seseorang yang berbeda antar satu orang dengan orang lain sehingga bisa saja seorang yang berolahraga merasakan nyeri perut yang hebat dengan ambang batas normal atau justru kebalikannya orang tidak berolahraga tidak bermasalah dengan nyeri perut meskipun dengan ambang batas yang tinggi. Kemungkinan lain tidak adanya hubungan dikarenakan adanya gejala penyerta dismenore lain selain olah raga yaitu nyeri pada pinggang, nyeri pada paha, mual, nyeri sendi, mudah marah, sakit kepala tidak dapat berkonsentrasi dll.

\section{Simpulan}

1. Karakteristik subjek penelitian yaitu masih banyak terdapat status gizi tidak normal pada mahasiswi, kebiasaan tidak melakukan olahraga lebih dari setengah mahasiswi kebidanan Rangkasbitung, dan sebagian besar mahasiswi mengalami dismenore. 
2. Tidak terdapat hubungan yang signifikan antara status gizi dengan kejadian dismenore.

3. Tidak terdapat hubungan yang signifikan antara olahraga dengan dismenore,

\section{Daftar Pustaka}

Anwar Mochamad (2011). Ilmu Kandungan. Prawirihardjo. Jakarta: PT Bina Pustaka Sarwono

Edmonds, K (2007). Gynaecological Disorders of Childhood and Adolescense : Dewhurst's Textbook of Obstetrics and Gynaecological 7thEdition. London: Blackwell Publishing.

Fritz, M \& Speroff L (2010). Clinical Gynecologic Endocrinology and Infertility. USA: Lippincott Williams \& Wilkins.

Giriwijoyo, S (2012). Ilmu Kesehatan Olahraga. Bandung : PT Remaja Rosdakarya

Lestari hesti, dkk (2010). Gambaran Dismenore pada Remaja Putri Sekolah Menengah Pertama di Manado. (Diunduh tanggal 16 april 2015). Diakses di: http://saripediatri.idai.or.id/pdfi le/12-2-7.pdf

Manuaba, I.B.G (2010). Ilmu Kebidanan, penyakit Kandungan \& Keluarga
Berencana untuk Pendidikan Bidan. Jakarta: EGC.

Marmi (2013). Kesehatan Reproduksi. Yogyakarta:

Pustaka Pelajar.

Mutohir, T.C (2004). Olahraga dan Pembangunan. Proyek Pengembangan dan Keserasian Kebijakan Olahraga Direktorat Jenderal Olahraga Departemen Pendidikan Nasional

Proverawati, A dan As Fuash,S (2009). Gizi Untuk Kebidanan . Yogyakarta: Nuha Medika.

Ramadani AN ( 2014). Hubungan Kebiasaan Olahraga Dengan Kejadian Dismenore Pada Siswi Di SMPN 2 Demak Tahun 2014.

Rayne (2014). Hubungan antara status gizi dengan kejadian dismenore pada siswi kelas XI SMA Negeri Kawangkoan

Sophia, Frenita, dkk (2013). Faktor faktor yang berhubungan dengan dismenore Pada siswi smk negeri 10 medan Tahun. (Diunduh tanggal 15 April 2015). Diakses di: http://jurnal.usu.ac.id/index.ph $\mathrm{p} / \mathrm{gkre} / \mathrm{article} / \mathrm{view} / 4060$

Sulistyoningsih, H (2012). Gizi untuk Kesehatan Ibu dan Anak. Yogyakarta: Graha Ilmu.

Supariasa I dkk, (2001). Penilaian Status Gizi. Jakarta : EGC 
Tjokronegoro, E (2004). Pendidikan

Jasmani dan Olahraga. Jakarta

: PT.

Rajagrafindo Persada Utami, Andi NR (2013). Faktor yang berhubungan dengan kejadian dismenore pada remaja putri di sman 1 kahu kabupaten bone. (Diunduh tanggal 15 April 2015). Diakses di: http://repository.unhas.ac.id/ha $\underline{\text { ndle/123456789/5523 }}$

Widyastuti, Yani dkk (2009). Kesehatan Repoduksi. Yogyakarta: Fitramaya.

Ernawati. Terapi ralaksasi terhadap nyeri dismenore pada mahasiswi Universitas Muhammadiyah Semarang 2010. (Diunduh tanggal 4 November 2015). Diakses di: http://jurnalunimus.ac.id 